\title{
Front Matter: Volume 10299
}

, "Front Matter: Volume 10299," Proc. SPIE 10299, Novel Materials and Crystal Growth Techniques for Nonlinear Optical Devices: A Critical Review, 1029901 (23 June 2000); doi: 10.1117/12.2284543

SPIE Event: Symposium on High-Power Lasers and Applications, 2000, San Jose, SPIE. CA, United States 


\section{Contents}

1 Review of fiber optics technology for military applications

P. B. Ruffin, U.S. Army Aviation and Missile Command

25 Dispersive and resonant properties of finite one-dimensional photonic band gap structures

C. M. Bowden, U.S. Army Aviation and Missile Command; M. Scalora, U.S. Army Aviation and Missile Command (USA) and Time Domain Corp. (USA);

M. J. Bloemer, U.S. Army Aviation and Missile Command; C. Sibilia, Univ. degli Studi di Roma La Sapienza (Italy); G. D'Aguanno, M. Centini, U.S. Army Aviation and Missile Command and Univ. degli Studi di Roma La Sapienza (Italy); M. Bertolotti, Univ. degli Studi di Roma La Sapienza (Italy)

87 Stepwise two-photon excitation studies in fibers and crystals for energy upconversion and infrared quantum counter devices

B. R. Reddy, Alabama A\&M Univ. (USA)

115 Nonlinear optical properties and applications of polydiacetylene H. A. Abdeldayem, M. S. Paley, NASA Marshall Space Flight Ctr. (USA) and Universities Space Research Association (USA); W. K. Witherow, D. O. Frazier, NASA Marshall Space Flight Ctr. (USA)

135 Growth and optical characterization of PTS polymer single crystals M. Liu, F. Yoshino, S. Polyakov, G. I. Stegeman, CREOL/Univ. of Central Florida (USA)

147 Light emission from silicon quantum dots

H. W. H. Lee, Lawrence Livermore National Lab. (USA); P. A. Thielen, Univ. of California/Davis (USA); G. R. Delgado, Lawrence Livermore National Lab. (USA); S. M. Kauzlarich, C.-S. Yang, Univ. of California/Davis (USA);

B. R. Taylor, Lawrence Livermore National Lab. (USA)

Novel Materials and Crystal Growth Techniques for Nonlinear Optical Devices: A Critical Review, edited by Ravindra B. Lal, Proc. øf SPIE Vol. 10299 (Vol. CR77), 1029901 - (c) (2000) 2017 SPIE

CCC code: $0277-786 \mathrm{X} / 17 / \$ 18 \cdot$ doi: $10.1117 / 12.2284543$ 